\title{
UMA REVISÃO SOBRE O USO DAS TICS NA EDUCAÇÃO DA GERAÇÃO Z
}

Guilherme Passero - guilherme.passero0@ gmail.com - UNIVALI, SOCIESC

Nélia Elaine Wahlbrink Engster - nelia.elaine@ sociesc.org.br - SOCIESC

Rudimar Luís Scaranto Dazzi - rudimar@ univali.br - UNIVALI

Resumo: A evolução das TICs transformou substancialmente as relações sociais. Apesar do interesse dos alunos pelas tecnologias e dos esforços estatais em promover a informática educativa, ainda existe dificuldade em incorporar as TICs à prática pedagógica. O objetivo desta pesquisa foi avaliar o impacto das TICs, em especial o computador e internet, na educação básica da Geração Z. Foram apresentados alguns efeitos negativos que as TICs têm causado em crianças e jovens e apontadas sugestões para o uso educacional seguro do computador. Também foi discutido o impacto da Geração Z nas práticas pedagógicas, onde se verificou a necessidade de uma educação centrada mais no aluno e menos no professor. Uma das expectativas deste trabalho é que as propostas citadas sejam amadurecidas e implementadas, e seu potencial de resolver os problemas apresentados seja verificado.

Palavras-chave: Tecnologias de Informação e Comunicação. Geração Z. Abordagem pedagógica.

\section{A REVIEW ON THE USE OF ICTS ON EDUCATION OF GENERATION Z}

Abstract: The evolution of ICTs substantially changed social relations. Despite the interest of students in technology and government efforts to promote education assisted by computers, there is still difficulty in incorporating ICT in teaching practice. The purpose of this literature review is to evaluate the impact of ICTs, especially the computer and internet, in basic education of Generation Z. Some negative effects of ICTs on children and teenagers were presented and suggestions on safe and educational use of computer were appointed. We also discuss the impact of Generation $Z$ on pedagogical practice, where the need for a student-centered education has been verified. With this research we expect that the mentioned pedagogical approaches are improved and implemented, and their potential to solve the presented problems is verified.

Key words: Information and Communication Technologies. Generation Z. Pedagogical approach.

\section{INTRODUÇÃO}

A evolução das Tecnologias de Informação e Comunicação (TICs) transformou substancialmente as relações sociais. Estamos cada vez mais usando dispositivos eletrônicos na interação com outras pessoas e o mundo. Embora o computador tenha trazido muitas facilidades para o mundo contemporâneo, trouxe também vários desafios.

A introdução de laboratórios de informática em $80,6 \%$ das escolas públicas brasileiras é uma evidência da preocupação do governo com a inclusão digital (INEP, 2014). Apesar do interesse dos alunos pelas tecnologias e dos esforços estatais em 
promover a informática educativa, ainda existe muita dificuldade em incorporar as TICs à prática pedagógica (SANTAELLA, 2010).

Alguns autores apontam evidências de que a exposição a TICs, principalmente antes da adolescência, pode trazer prejuízos sérios, e o uso de laboratórios de informática no ensino fundamental requer atenção (SETZER, 2014; CARR, 2011).

Haja vista esse potencial negativo das TICs e a sua emergência no ambiente educacional, torna-se imprescindível estudar como utilizá-las de modo seguro e benéfico. Nesse sentido, através de uma revisão narrativa da literatura, esta pesquisa visa: (i) apresentar os efeitos negativos das TICs em crianças e jovens da Geração Z; (ii) averiguar meios potencialmente seguros para uso educacional do computador; e (iii) avaliar os desafios que a Geração $\mathrm{Z}$ trouxe para a prática pedagógica.

O conteúdo desse trabalho foi estruturado na seguinte forma: no tópico 2 a Geração Z é brevemente caracterizada; no tópico 3 são abordados os efeitos negativos que as TICs têm causado nessa nova geração; no tópico 4 é apresentada a situação atual das TICs nas escolas e discutida a dificuldade em conciliar essas tecnologias à prática pedagógica; no tópico 5 são propostas mudanças na abordagem pedagógica perante a Geração Z; no tópico 6 sugere-se mudanças na forma como as TICs são utilizadas em casa e na escola; por fim, discute-se as contribuições desse trabalho e são apresentadas sugestões de trabalhos futuros.

\section{A GERAÇÃO Z}

O exponencial aumento no uso de computadores visto nas últimas décadas deu origem a uma nova geração multitarefa, imediatista e falante da "linguagem digital". Essa geração tem sido referenciada como a "Geração Z". O Z vem do inglês "zapping" e se refere a mudar canais rapidamente quando assistimos à $T V$, ignorando os que não nos interessam. Essa troca constante de "canais" - de informação - é normalmente observada nessa geração (TOLEDO; ALBUQUERQUE; MAGALHÃES, 2012).

A Geração Z também tem sido chamada de "nativos digitais", "Geração Net", "e-generation", "Homo sapiens digitalis", "iGen", "Post-Millennials" entre outros nomes. Os nativos digitais são aqueles nascidos após 1995, quando o uso da internet se intensificou no globo e começaram a fazer parte do meio infantil tecnologias como Wi-Fi, smartphones, tablets, jogos on-line e serviços virtuais de comunicação e socialização (MEIRINHOS, 2015).

$\mathrm{O}$ advento da Era Digital trouxe mudanças tão significativas para o ser humano que às vezes é comparado a outros grandes marcos da história, como o surgimento da linguagem e o da imprensa. As tecnologias são extensões das capacidades humanas e assim como o homem transforma seu ambiente, o ambiente transforma o homem. As tecnologias digitais estão alterando o funcionamento do homem e criando uma relação de dependência (MEIRINHOS, 2015; SANTAELLA, 2010).

\section{EFEITOS NEGATIVOS DAS TECNOLOGIAS NA GERAÇÃO Z}

O processo cognitivo dos nativos digitais sofreu mudanças significativas com as novas TICs. Esse fato já é bem aceito na comunidade científica (CARR, 2011; MEIRINHOS, 2015; SETZER, 2014; TAPSCOTT, 2010; SANTAELLA, 2010). Segundo Meirinhos (2015), as novas formas de interação homem-computador "alteram o que sabemos, a forma como pensamos, a forma como vemos o mundo e como nos relacionamos, como atuamos e como aprendemos". 
Carr (2011) ratifica a importância de uma revisão das alterações cognitivas que as novas tecnologias têm causado. Também evidencia a diminuição da nossa capacidade intelectual gerada pela forma como a web é apresentada: "as pesquisas continuam a mostrar que as pessoas que leem textos lineares [preferencialmente no papel] compreendem mais, lembram mais e aprendem mais do que aquelas que leem textos salpicados com links [na internet]" (p. 177).

Ao usar o computador ou celular, somos constantemente notificados sobre o que acontece no mundo, publicações que nos envolvem, mensagens recebidas, atualizações de aplicativos etc. Esse "bombardeio" de informações digitais afeta nossa concentração e prejudica seriamente nossa capacidade de aprender. Carr (2011) classifica a web como uma "tecnologia do esquecimento", pois obstrui nossas faculdades de raciocínio mais elevado e interrompe a consolidação de memórias de longo prazo e o desenvolvimento de esquemas mentais.

Em uma avaliação recente da Organização para a Cooperação e Desenvolvimento Econômico (OECD) sobre os resultados do exame de 2012 do Programa Internacional de Avaliação de Alunos (PISA), realizado em 65 países, constatou-se que países que investiram extensivamente em computadores e novas tecnologias nas escolas não tiveram melhora significativa na performance dos alunos em leitura, matemática e ciências (OECD, 2015).

Woessmann e Fuchs (2004) também avaliaram os resultados do exame do PISA, edição de 2000, considerando o uso do computador em casa. Os autores constataram que a mera disponibilidade de computador no lar está significativamente associada a um baixo rendimento escolar. No entanto, verificou-se que o uso moderado do computador em casa ou na escola, quando com fins educacionais, estava relacionado a um melhor rendimento escolar.

Outro estudo (SPRIETSMA, 2012) avaliou os resultados de português e matemática do SAEB - Sistema de Avaliação da Educação Básica (do Brasil) - e constatou uma forte relação entre a disponibilidade de laboratórios de informática na escola e um menor rendimento escolar. Diferentemente do estudo supracitado, esta constatação não considera a frequência e o modo de uso do computador.

Houve também um estudo brasileiro (DWYER et al., 2007) sobre o SAEB 2011, que concluiu que o uso intenso do computador tem diminuído o desempenho escolar. Ao considerar a classe socioeconômica, constatou que estudantes mais pobres tinham um rendimento escolar prejudicado mesmo com o uso moderado do computador.

Setzer (2014) cita esses e muitos outros estudos ao redor do mundo que demonstraram uma influência negativa do computador no rendimento escolar. Também alerta sobre alguns problemas que os nativos digitais estão sofrendo possivelmente devido a como usam as TICs (especialmente TV, video games e computador): excesso de peso e obesidade; problemas de atenção e hiperatividade; agressividade e comportamento antissocial; isolamento, depressão e medo; dessensibilização dos sentimentos; confusão de fantasia com realidade; aceleração do desenvolvimento; prejuízo para a criatividade; vício; indução ao consumismo. Para conhecer diversos estudos relacionados a esses problemas sugere-se consultar (SETZER, 2014).

Setzer (2014) defende que o uso do computador e da internet exige, para não ser prejudicial, um alto grau de conhecimento, discernimento e autocontrole inexistentes ou incipientes na infância e adolescência. Esse autor compara deixar uma criança sem supervisão ao computador com deixar essa criança em uma rua desconhecida: nas duas situações a criança está vulnerável a pessoas mal-intencionadas, locais e materiais impróprios e a gastar seu tempo excessivamente em atividades não construtivas. $\mathrm{O}$ autor 
ainda cita os estágios do desenvolvimento humano segundo a pedagogia Waldorf, ressaltando o conflito do sistema lógico-simbólico imposto pelo computador com um menor impúbere, em que o pensamento não é formal e lógico (SETZER, 2001).

Outros autores também criticam o uso do computador na educação dos jovens:

Estamos usando tecnologias computacionais porque elas ensinam melhor ou porque perdemos vontade política de consolidar uma educação adequada? (TURKLE, 1997, p. 80)

Minha preocupação é de que estamos expondo os alunos a muitas versões controladas e fabricadas da realidade e não à natureza como ela realmente é. (HAYBRON, 1996, p. 8E)

"[A preocupação de muitos é que] eles estão viciados em telas, viciados em internet, perdendo suas habilidades sociais, e não têm tempo para esportes e atividades saudáveis. O tempo gasto online poderia ser aplicado em esportes e conversas face a face; o resultado é uma geração de pessoas desajeitadas e gordas.” (TAPSCOTT, 2010, p. 3)

Apesar de todos os problemas citados anteriormente, muitos autores são mais otimistas e defendem que as TICs são uma realidade do mundo contemporâneo, e a sociedade, inclusive os sistemas educacionais, precisam se adaptar. Não obstante muitos estudos associarem o computador a problemas cognitivos e sociais, ainda há necessidade de novos estudos a fim de estabelecer meios seguros de usufruir dos benefícios do computador.

As evidências até o momento não sugerem que o computador seja totalmente banido, mas que seu uso seja regulado. A Geração Z, moldada pela forma como o computador é usado hoje - que talvez não seja a mais saudável -, é um novo perfil de estudante que tem desafiado os professores. Os autores abaixo discorrem sobre a nova realidade do ambiente escolar e as expectativas dessa geração tecnológica:

As redes de aprendizagem digital permitem expandir a aprendizagem escolar muito para além dos seus muros. A interação e colaboração a distância é hoje uma realidade e são necessárias novas abordagens pedagógicas para poder tirar proveito educativo da comunicação e acesso à informação virtualizada. (MEIRINHOS, 2015, p. 3)

São desenvolvidas novas expectativas de liberdade, flexibilidade em relação ao momento e ao local da prática, uma necessidade de instantaneidade que se opõe às práticas culturais tradicionais. (SANTAELLA, 2010, p. 21)

As redes de computadores oferecem uma perspectiva muito diferente do computador isolado. Rompe-se o isolamento tradicional das salas de aula, abrindo-as para o mundo. Permitem a comunicação entre as pessoas eliminando as barreiras do espaço e tempo, identidade e status social. (ADELL, 1997, p. 18)

A maioria das críticas se baseia em desconfiança e medo, geralmente por parte de pessoas mais velhas. Esses temores talvez sejam compreensíveis. A nova rede, nas mãos de uma nova Geração Internet tecnologicamente preparada e com uma mentalidade comunitária, tem o poder de abalar a sociedade e derrubar autoridades em várias áreas. [...] a vida como nós a conhecemos se torna diferente. (TAPSCOTT, 2010, p. 17)

\section{A ENTRADA DAS TICS NA ESCOLA}

Apesar de a UNESCO (WEST; VOSLOO, 2013) recomendar o uso de celulares como ferramenta de aprendizado, a maioria das escolas brasileiras proíbe o uso do 
celular na sala de aula por regimento interno ou em conformidade com a legislação. Os alunos estão insatisfeitos com o "atraso" da escola e o seu relativo isolamento do mundo tecnológico. Sem o consentimento ou orientação do professor, os alunos utilizam seus celulares para "agendar suas tarefas, consultar dicionários e enciclopédias, pesquisar sobre temas que aprendem em aula, registrar lousas e quadros de aviso por meio de imagens, trocar informações com colegas e até mesmo praticarem outras línguas" (ANTONIO, 2014, p. 4).

O aumento no acesso ao computador e internet, seja na escola ou em casa, significa um aumento no acesso à informação. Santaella (2010) explica o termo "aprendizagem ubíqua" como a possibilidade de aprender sobre qualquer coisa em qualquer momento e local utilizando as tecnologias móveis conectadas à internet. No entanto, a simples disponibilidade de informação na internet não gera aprendizagem e a autora reconhece que a "aprendizagem ubíqua" não substitui, mas complementa a educação formal, informal e não formal. Assim, talvez um termo mais preciso para essa realidade seria "informação ubíqua".

Embora 80,6\% das escolas públicas brasileiras tenha laboratório de informática, apenas $46 \%$ dos professores utilizam o computador para fins educativos. Esse número é expressivo quando comparado ao levantamento de 2011, que aferiu 22\% (INEP, 2014; BARBOSA, 2014). Essas e outras evidências mostram que os professores estão preocupados em incorporar as novas TICs a sua prática pedagógica e esse processo se intensificou nos últimos anos. Vale ressaltar que o aumento no uso do computador em sala de aula, de acordo com os estudos já citados, não implica necessariamente uma educação melhor.

O estudo de Sprietsma (2012) encontrou uma relação positiva entre o uso da internet pelo professor e o rendimento dos alunos. Felizmente, segundo pesquisa do Comitê Gestor da Internet no Brasil (BARBOSA, 2014), 96\% dos professores de escolas públicas já usam recursos da internet no preparo de suas aulas. Contudo, além de um professor atualizado, usuário da internet, os alunos digitais querem também mudanças na prática pedagógica.

\section{MUdANÇAS NA PRÁTICA PEDAGÓGICA}

O modelo tradicional de educação centrada no professor, onde este é o detentor da informação, não se aplica mais na Era Digital. Agora, a informação está disponível na internet e os alunos não dependem mais do professor para obtê-la. No entanto, para que a aprendizagem aconteça, a presença do professor continua sendo fundamental. Pois enquanto o aluno estiver sozinho ao computador, estará navegando num "mar" de informações dispersas, possivelmente perdido, propenso a atividades não construtivas.

Tantos esforços em usar o computador na educação não trarão resultados se a prática pedagógica não for reavaliada. Os nativos digitais estão "famintos" por informação dinâmica e diversificada e desse modo têm desafiado a tradicional educação centrada no professor. Tapscott (2010), em um extenso estudo de caracterização das novas gerações, criou oito normas para a "Geração Internet":

1. Liberdade - de expressão e de escolha;

2. Customização - das experiências de consumo, de trabalho e de educação;

3. Escrutínio - atenção aos detalhes;

4. Integridade - como sinônimo de lealdade e transparência;

5. Colaboração - algo natural para a nova geração; 
6. Entretenimento - essencial em todas as atividades, inclusive no trabalho e na escola: gostar do que se faz nunca foi tão importante;

7. Velocidade - rapidez na obtenção de um bem, material (um produto) ou abstrato (conhecimento);

8. Inovação - cultural e acontece em tempo real.

Assim, para Tapscott (2010), o desafio para os sistemas educacionais é propiciar um ambiente de aprendizagem que valorize essas oito normas.

Meirinhos (2015) aponta algumas abordagens pedagógicas promissoras para a educação da Geração Z: conectivismo, Flipped Classroom, autorregulação e coassociação. Essas abordagens apresentam alguns princípios em comum, entre eles a educação centrada no aluno, onde o professor atua como problematizador e facilitador e o aluno é instigado à pesquisa dinâmica e colaborativa.

Além de mudanças na prática pedagógica, são necessárias mudanças na forma como o computador é usado pelos alunos da educação básica. Haja vista os problemas destacados por Carr (2011) e Setzer (2014), como o prejuízo à cognição e o isolamento, torna-se necessário estabelecer meios seguros de utilizar o computador de modo a potencializar o aprendizado.

\section{MUDANÇAS NO MODO DE UTILIZAÇÃO DO COMPUTADOR}

Apesar de Woessmann e Fuchs (2004) terem encontrado uma influência negativa da presença do computador no rendimento escolar, ao aprofundar sua análise verificaram que o uso moderado do computador para fins educacionais esteve associado a um melhor desempenho em português e matemática. Na avaliação dos resultados do PISA em 2015, também se observou uma relação entre o uso moderado do computador na escola e melhor performance no exame (OECD, 2015). Essa melhora nas habilidades de intepretação e cálculo mostra que talvez, se usado de modo adequado, os efeitos negativos na capacidade cognitiva apresentados no tópico 3 são contornáveis.

A pesquisa de Dwyer et al. (2007) também traz informações que ajudam a esclarecer os malefícios do computador. Os autores constataram que quanto mais pobre o aluno, pior a influência do computador no seu rendimento escolar. Por outro lado, alunos de classes sociais mais altas que usavam o computador moderadamente tiveram resultados positivos. Novamente, é evidente a possibilidade do uso adequado do computador associar-se a resultados escolares melhores.

Segundo Setzer (2014), idealmente o computador deveria ser introduzido na vida do jovem somente quando este compreende todos os aspectos positivos e negativos dessa ferramenta. No entanto, abolir totalmente o computador é algo inviável na maioria dos lares, pois os computadores estão nas escolas, nas bibliotecas, na casa dos amigos etc. Desse modo, na maioria dos casos, a criança inevitavelmente entrará em contato com o computador antes de atingir a maturidade. Há de se considerar também os potenciais efeitos positivos do computador na educação já mencionados.

Assim, Setzer (2014) sugere que o uso do computador e internet antes da maturidade seja sempre supervisionado por um adulto, que na escola normalmente será o professor e em casa os pais. $\mathrm{O}$ adulto suplementará o senso de autorregulação não desenvolvido na criança: orientando sobre o uso seguro do computador; gerenciando as atividades realizadas (adequadas à idade e prioritariamente educacionais); controlando o tempo gasto no computador; impedindo a interação com pessoas mal-intencionadas; e 
prevenindo a indução ao consumismo do marketing digital, que hoje não é devidamente regulado.

É necessário também considerar a capacidade natural da internet de induzir ao déficit de atenção, como constatado nos diversos estudos analisados por Carr (2011). Esse problema pode ser amenizado ou eliminado com a prática de ler textos eletrônicos de modo linear, ignorando links que levariam o leitor a outras páginas e se protegendo dos "bips eletrônicos" (p. ex. avisos de mensagens e feeds de notícias) (SETZER, 2014).

Jogos e vídeos violentos devem ser retirados da proximidade da criança e do jovem, pois sua capacidade de dessensibilização dos sentimentos traz perceptíveis consequências sociais (SETZER, 2014). Além disso, ao induzir uma zona de conforto dentro de um ambiente violento real, pode diminuir a criatividade, pois desestimula a procura por soluções para problemas comuns.

A TV, quando sem fins educacionais, deve ser evitada nos ambientes com bebês, crianças ou adolescentes, haja vista os numerosos estudos que relacionam a TV a problemas no desenvolvimento cognitivo, maior chance de falhar socialmente, obesidade, agressividade, depressão, isolamento etc. (SETZER, 2014).

\section{CONSIDERAÇÕES FINAIS}

Este estudo identificou e discutiu algum dos efeitos que as TICs, principalmente computador e internet, causam nas crianças e jovens nativos digitais.

Apesar de tantos problemas associados ao uso das TICs pela Geração Z, o computador não pode ser considerado o vilão. O computador é uma tecnologia criada pelo homem para o homem e, por si só, não é prejudicial, é o modo que o utilizamos que determina seus efeitos. O computador deve ser usado de modo consciente, assim como qualquer outra tecnologia, de modo que seus efeitos adversos sejam superados pelos efeitos positivos desejados.

Considerando as características e necessidades da Geração Z identificadas por Tapscott (2010), verificou-se a necessidade de uma abordagem pedagógica centrada mais no aluno e menos no professor. Ainda, foram apresentadas algumas sugestões de mudanças em como o computador é utilizado dentro do ambiente escolar e em casa, visando suplementar a falta de maturidade de crianças e jovens para o uso seguro e benéfico do computador.

A incorporação das TICs nos sistemas educacionais é um trabalho em andamento. Sugere-se para trabalhos futuros: avaliar a implementação das abordagens pedagógicas apresentadas; estabelecer meios seguros de uso de TICs dentro e fora da escola; estudar o uso do celular dentro da sala de aula; e avaliar o impacto da proposta de regulação do uso do computador por crianças e jovens na vida escolar.

\section{REFERÊNCIAS}

ADELL, Jordi. Tendencias en educación en la sociedad de las tecnologías de la información. Edutec. Revista electrónica de tecnología educativa, n. 7, 1997.

ANTONIO, José Carlos. A escola nativa digital e seus professores órfãos pedagógicos. Professor Digital, SBO, v. 17, 2014. 
BARBOSA, A. Pesquisa sobre o uso das tecnologias de informação e comunicação nas escolas brasileiras: TIC Educação 2013. São Paulo: Comitê Gestor da Internet no Brasil, 2014.

CARR, Nicholas. A geração superficial: o que a internet está fazendo com os nossos cérebros. Rio de Janeiro: Agir, 2011.

DWYER, Tom et al. Desvendando mitos: os computadores e o desempenho no sistema escolar. Educação \& Sociedade, v. 28, n. 101, p. 1303-1328, 2007.

HAYBRON, R. Too much emphasis on computers. Cleveland Plain Dealer, p. 8E, 1996.

INEP. Censo Escolar da Educação Básica 2013: Resumo técnico. Brasília: O Instituto, 2014.

MEIRINHOS, Manuel. Os desafios educativos da geração Net. Revista de Estudios e Investigación en Psicología y Educación, n. 13, p. 125-129, 2015.

OECD. Students, Computers and Learning: Making the Connection. Paris: OECD, 2015.

SANTAELLA, Lúcia. A aprendizagem ubíqua substitui a educação formal. Revista de Computação e Tecnologia da PUC-SP_Departamento de Computação/FCET/PUC-SP, vol. II, nº 1, 2010.

SETZER, Valdemar W. Efeitos negativos dos meios eletrônicos em crianças, adolescentes e adultos, 2014. Disponível em <http://www. ime. usp. br/ vwsetzer/efeitos-negativosmeios. html>. Acessado em 26 jan. 2016.

2001.

Os meios eletrônicos e a educação: televisão, jogo eletrônico e computador.

SPRIETSMA, Maresa. Computers as pedagogical tools in Brazil: a pseudo-panel analysis. Education Economics, v. 20, n. 1, p. 19-32, 2012.

TAPSCOTT, Don. A hora da geração digital: como os jovens que cresceram usando a internet estão mudando tudo, das empresas aos governos. Rio de Janeiro: Agir Negócios, 2010.

TOLEDO, Priscilla B. F.; ALBUQUERQUE, Rosa A. F.; MAGALHÃES, Ávilo R. O Comportamento da Geração Z e a Influencia nas Atitudes dos Professores. In: IX SIMPÓSIO DE EXCELÊNCIA EM GESTÃO E TECNOLOGIA - SEGeT, 2012, Rio de Janeiro. Anais... Rio de Janeiro: AEDB, 2012.

TURKLE, Shebry. Seeing through computers. American Prospect, 1997.

WEST, Mark; VOSLOO, Steven. UNESCO policy guidelines for mobile learning. Paris: UNESCO. v. 21, p. 002196, 2013.

WOESSMANN, Ludger; FUCHS, Thomas. Computers and student learning: Bivariate and multivariate evidence on the availability and use of computers at home and at school. 2004. 